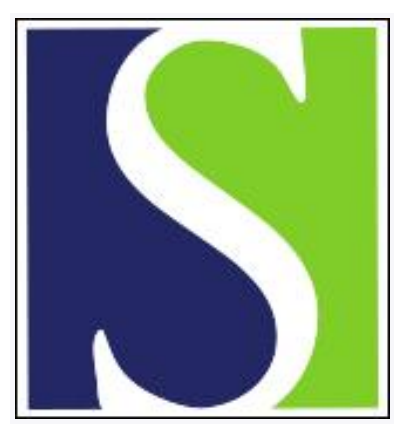

Scand J Work Environ Health 2008;34(5):396-402

https://doi.org/10.5271/sjweh.1275

Published online: 14 Oct 2008, Issue date: 00 Oct 2008

Prevalence and characteristics of functional dyspepsia among workers exposed to cement dust

by Coppeta L, Pietroiusti A, Magrini A, Somma G, Bergamaschi A

Affiliation: Department of Biopathology-Occupational Medicine, Tor Vergata University, Via Montpellier 1, 00161 Rome, Italy. coppeta@med.uniroma2.it

Key terms: cement dust; exposure; exposure level; functional dyspepsia; occupational exposure; prevalence; reflux-like dyspepsia; symptom severity; ulcer-like dyspepsia; worker

This article in PubMed: www.ncbi.nlm.nih.gov/pubmed/18853070 


\title{
Prevalence and characteristics of functional dyspepsia among workers exposed to cement dust
}

\author{
by Luca Coppeta, MD, ${ }^{1}$ Antonio Pietroiusti, MD,${ }^{1}$ Andrea Magrini, MD, ${ }^{1}$ Giuseppina Somma, MD, ${ }^{1}$ \\ Antonio Bergamaschi, MD²
}

\begin{abstract}
Coppeta L, Pietroiusti A, Magrini A, Somma G, Bergamaschi A. Prevalence and characteristics of functional dyspepsia among workers exposed to cement dust. Scand J Work Environ Health 2008;34(5):396-402.
\end{abstract}

\begin{abstract}
Objectives No data are currently available on the prevalence and characteristics of functional dyspepsia among cement workers. Given the potential impact of dyspepsia on work performance, whether its prevalence is increased among workers exposed to cement dust was evaluated.

Methods Altogether 420 cement workers were enrolled in the study. According to the individual exposure levels to cement dust, the following three groups were established: no exposure (128 workers), low exposure $\left(<1 \mathrm{~g} / \mathrm{m}^{3}, 116\right.$ workers), and high exposure $\left(>1 \mathrm{mg} / \mathrm{m}^{3}, 176\right.$ workers). Dyspepsia was evaluated by means of validated questionnaires.

Results The prevalence of dyspepsia was increased in both the low and high exposure groups in comparison with the unexposed workers $(51.7 \%$ and $59.1 \%$, respectively, versus $34.4 \%$; adjusted odds ratio (aOR) $2.21,95 \%$ confidence interval (95\% CI) 1.25-3.92, and aOR 2.36, 95\% CI 1.31-4.25, respectively). A stepwise regression analysis showed a progressive increase in the odds ratio for dyspepsia for the low- and high-exposure groups with the no-exposure group as reference (OR 1.94, 95\% CI 1.15-3.27, and OR 2.61, 95\% CI 1.62-4.20, respectively). Ulcer-like dyspepsia was especially associated with the degree of exposure to cement dust, $11.71 \%$ for the noexposure group versus $17.24 \%$ for the low-exposure group versus $29.54 \%$ for the high-exposure group (aOR 3.49, 95\% CI 1.60-7.63), when the high-exposure group was compared with the no-exposure group. Similar findings were obtained for reflux-like dyspepsia.

Conclusions Occupational cement-dust exposure is associated with dyspepsia, and the association is particularly strong for ulcer-like and reflux-like dyspepsia.
\end{abstract}

Key terms exposure level; occupational exposure; reflux-like dyspepsia; symptom severity; ulcer-like dyspepsia.

It has been speculated that cement dust may induce chronic gastric inflammation when coming in contact with gastrointestinal mucosa (1). Epidemiologic data about the possible association of cement-dust exposure with organic lesions of the upper-gastrointestinal tract are, however, conflicting (2-9), probably because the reliability of the aforementioned studies was generally limited by their retrospective nature and by methodological pitfalls.

In spite of the debate on the possible association between cement-dust exposure and organic lesions of the upper-gastrointestinal tract, no data are currently available on the possible association with functional dyspepsia, which is much more common and may have a strong influence on work performance (10-12).

This lack of data may depend on the fact that no clear classification and no scoring system for dyspeptic symptoms have been available until recently, and it has therefore been very difficult to assess this disorder objectively and make a comparison between different studies. In recent years, however, internationally validated criteria for classifying and quantifying dyspeptic symptoms have been developed (13).

The aim of our current study was to evaluate whether the prevalence and intensity of dyspeptic symptoms are increased among workers exposed to cement dust and whether a dose-response relationship exists.

\section{Study population and methods}

In 2006, we recruited workers on a voluntary basis from two cement factories located in the same geographic area (the Lazio District) of central Italy. People were

1 Department of Biopathology-Occupational Medicine, Tor Vergata University, Rome, Italy.

2 Institute of Occupational Medicine, Catholic University of the Sacred Heart, Rome, Italy.

Correspondence to: Dr A Pietroiusti, Department of Biopathology-Occupational Medicine, Tor Vergata University, Via Montpellier 1, 00161 Rome, Italy. [E-mail: pietroiusti@med.uniroma2.it] 
considered for the study if they had worked in the same worksite of the cement factory during the last 5 years. The exclusion criteria were the presence of systemic inflammatory or immunologic disorders, the coexistence of diabetes or other metabolic diseases, the presence of neoplasia, a previous diagnosis of organic disorders of the upper-gastrointestinal tract (ie, peptic ulcer or cancer of the stomach or esophagus), previous attempts at $\mathrm{He}$ licobacter pylori eradication, gallbladder disease, maintenance therapy with $\mathrm{H}_{2}$-receptor antagonists or proton pump inhibitors, and the development of dyspeptic symptoms before being employed at the cement plant. Dyspeptic workers with alarming signs and symptoms (weight loss, anemia, anorexia, upper-gastrointestinal bleeding) were also excluded from the study and were recommended to get an appropriate diagnostic work-up; those with a high-risk condition (development of dyspepsia after the age of 50 years or with a family history of gastric cancer) were recommended to undergo uppergastrointestinal endoscopy. Those reporting a normal endoscopic examination were included in the study, whereas those with abnormal findings and those refusing to perform the endoscopic control were excluded. All of the enrolled participants were men.

At least two measurements per year of personal exposure to cement dust had to be available during the last 5 (range $2-3$, median 2 ) years, and the mean value of the measurements was taken as the mean level of exposure. The three levels of exposure of absent (exposure below the detection limit), low $\left(<1 \mathrm{mg} / \mathrm{m}^{3}\right)$, and high $(>1 \mathrm{mg} /$ $\mathrm{m}^{3}$ ) were established a priori. These limits were selected on the basis of available guidelines regarding the risk of respiratory disorders after occupational exposure to cement dust (14). In fact, according to these guidelines, the threshold limit for cement dust is $10 \mathrm{mg} / \mathrm{m}^{3}$, and one-tenth of the threshold limit (in this case $1 \mathrm{mg} / \mathrm{m}^{3}$ ) is commonly taken as the "attention level" beyond which adverse respiratory effects cannot be excluded.

Measurements of dust particles were expressed according to the European standard norm (15). We chose to consider the inhalable fraction because it is the mass fraction of particles that can be inhaled by the nose or mouth, with the highest median size of the particles $(100 \mu \mathrm{m})$, in comparison with other measurable fractions, such as the respirable fraction (median size $4.25 \mu \mathrm{m}$ ) and thoracic fraction (median size $11.6 \mu \mathrm{m}$ ). This choice was determined according to the consideration that larger particles may have more probabilities of being entrapped in the mouth or nose and of being subsequently swallowed. The level of the inhalable fraction was assessed by the gravimetric method, which is based on the collection of the inhalable fraction samples on filters made of polyvinyl chloride at a flow rate of $2.2 \mathrm{l} / \mathrm{min}$.

The presence and degree of dyspepsia were evaluated according to the Rome II criteria, which were es-

tablished in 1999 on the basis of the consensus opinion of an international panel of clinical investigators (13) and have been extensively used thereafter (16-18). A typical participant required approximately 10 minutes to complete the entire questionnaire. Interviewers checked the questionnaires for completeness on site and gave clarifications on the meaning of terms not readily understood by the workers.

The questionnaire investigates the presence of six different symptoms (epigastric pain, epigastric discomfort, bloating, fullness, early satiety, nausea), and a diagnosis of dyspepsia was made in the presence of at least one symptom for at least 12 weeks in the past 12 months.

According to the prevalent symptom, three types of dyspepsia were identified, ulcer-like dyspepsia (when epigastric pain is the predominant symptom), dismotility-like dyspepsia (when epigastric discomfort is the predominant symptom), and nonspecific dyspepsia.

In addition, we also evaluated the presence of heartburn and acid regurgitation. The participants reporting either symptom as predominant were classified as having reflux dyspepsia.

The intensity of each dyspeptic symptom was evaluated by means of a visual analogue scale $(0-100 \mathrm{~mm}$, corresponding to absence and maximum intensity) that resulted in the construction of a summary symptom score (19).

Finally, a Likert scale was used to quantify the frequency of symptoms during the last 3 months among the workers with a diagnosis of dyspepsia $(1=\leq 1$ week, $2=$ 2-3 times/week, 3 = 4-6 times/week, 4 = everyday).

All of the workers were investigated for other variables of potential influence on dyspeptic symptoms, such as age, smoking, coffee and alcohol consumption, nonsteroidal anti-inflammatory drug intake (NSAID), work seniority, and pattern of daily workhours (daily or shift workers).

The interviewers were unaware of the exposure level of the workers.

Informed written consent was obtained from all of the workers participating in the study, which was approved by the ethics committee of our institution.

The following baseline characteristics were categorized: age ( $<35,35-55$, and $>55$ years); body mass index (BMI), expressed as kilograms per square meter (above and below 25); alcohol intake, evaluated considering 110 grams of alcohol per liter of wine, 44 grams of alcohol per liter of beer, and 350 grams of alcohol per liter of spirit (above and below $30 \mathrm{~g} /$ day); coffee intake (above and below 3 cups per day); smoking status (yes or abstinence for $<6$ months and no or abstinence for $>6$ months); NSAID intake (above and below 2 times/ week); and daily workhours (shift workers and nonshift workers). 
When not otherwise stated, the data have been expressed as the means and standard deviations of the means. A two-tailed P-level of $<0.05$ was taken as evidence of significance. The chi-square test and Student's t-test were used for the comparison of discrete and continuous variables, respectively. Odds ratios (OR) and $95 \%$ confidence intervals (95\% CI) adjusted for age, alcohol, and smoking were calculated by means of a multiple logistic regression when the prevalence of different subtypes of dyspepsia and the cumulative prevalence of dyspepsia were compared among the groups of workers with a different degree of exposure to cement dust. Furthermore, adjusted odds ratios (aOR) and $95 \%$ confidence intervals were calculated for the presence of dyspepsia using a forward stepwise logistic regression involving an evaluation of variables considered to be potentially linked to dyspepsia (age class, smoking, coffee and alcohol consumption, frequency of NSAID intake, degree of exposure to cement dust, BMI, and work schedule) and using the unexposed persons as the reference group. Variables with P-values of $<0.20$ were allowed in the final model.

The chi-square test for trend was used for analyzing the distribution of the symptom frequency in the four classes of the Likert scale for the exposed and unexposed workers.

The statistical analysis was performed with Intercooled Stata 9.2 software (release 9, StataCorp LP, College Station, TX, USA).

\section{Results}

The whole eligible worker population comprised 511 male workers, 503 of whom participated in the study. Altogether 83 workers were, however, excluded from the study for the following reasons: lack of sufficient exposure data (14 workers), systemic disorders (4 workers), gallbladder disease (1 worker), previous diagnosis of peptic ulcer (3 workers), nongastrointestinal neoplasia ( 2 workers), alarming symptoms ( 7 workers), dyspeptic workers aged $\geq 50$ years, with abnormal findings in an upper-gastrointestinal endoscopy or refusing to perform endoscopy (6 workers), previous $H$ pylori eradication (3 workers), maintenance therapy with $\mathrm{H}_{2}-$ receptor antagonists or proton pump inhibitors (6 workers), $<5$ years of employment ( 22 workers), and development of symptoms before employment (15 workers). The data therefore refer to 420 workers.

According to our exposure criteria, 128 workers were classified as having no exposure (all of the exposure evaluations fell into this class), 116 as having low exposure ( 9 workers had one exposure evaluation in the high-exposure range and any others in the low-exposure range), and 176 as having high exposure (12 workers had one exposure evaluation in the low exposure range and any others were in the high-exposure range).

The main clinical characteristics of the exposed and unexposed workers are shown in table 1.

Smokers were found with increased frequency among the unexposed workers in comparison with those with high exposure (53.13\% versus $36.36 \%$ ), whereas workers with a high level of alcohol intake were detected more frequently among the workers with low exposure in comparison with those with high exposure $(37.93 \%$ versus $18.18 \%$ ).

The prevalence and type of dyspepsia of the three groups of workers are shown in table 2.

Dyspepsia was diagnosed with increased frequency among those with low exposure $(51.72 \%)$ or high exposure $(59.08 \%)$ in comparison with the unexposed workers $(34.35 \%)$ (aOR 2.21, 95\% CI 1.25-3.92, and aOR $2.36,95 \%$ CI $1.31-4.25$, respectively). The prevalence of ulcer-like dyspepsia was significantly higher in the high-exposure group than in the low-exposure group $(29.54 \%$ versus $17.24 \%$, aOR $1.94,95 \%$ CI $1.08-3.18)$ or in the no-exposure group (29.54\% versus $11.71 \%$, aOR $3.49,95 \%$ CI 1.60-7.63). Both the lowand high-exposure groups showed a significantly higher prevalence of reflux-like dyspepsia $(24.14 \%$ and $25 \%$, respectively) in comparison with the no-exposure group $(11.71 \%$ ) (low exposure versus no exposure: OR 2.44, 95\% CI 1.22-3.89; high exposure versus no exposure: OR 2.48, 95\% CI 1.31-4.01). Dismotility-like dyspepsia and unspecified dyspepsia did not differ significantly among the three groups.

The prevalence of each symptom in the three groups is shown in table 3 .

Bloating was reported with increased frequency among the workers with low exposure than among those with no exposure $(\mathrm{P}=0.0001)$. The following symptoms were detected with increased frequency in the high-exposure group in comparison with the no-exposure group: nausea $(\mathrm{P}=0.001)$, bloating $(\mathrm{P}<0.0001)$, and epigastric pain $(\mathrm{P}=0.03)$. The frequency of nausea and epigastric pain was significantly higher in the high-exposure group in comparison with the low-exposure group $(\mathrm{P}=0.03$ and $\mathrm{P}=0.02$, respectively).

In all of the groups, the Likert score (for the frequency of symptoms among the dyspeptic patients during the last 3 months) ranged from 1 to 4 (table 4). The distribution of patients in the four classes differed among the three groups. In the no-exposure group, there was a clear trend for an increased prevalence of low-frequency symptoms ( $\mathrm{P}$ for trend $=0.002$ ), which was of borderline statistical significance for the low-exposure group $(\mathrm{P}$ for trend $=$ 0.052), whereas a similar distribution in the prevalence of frequent and infrequent symptoms was found in the high-exposure group $(\mathrm{P}$ for trend $=0.69$ ) . 
Table 1. Clinical characteristics of the workers, according to their degree of exposure. $(P=0.0002$ when comparing alcohol consumption between the high- and low-exposure groups, $\mathrm{P}=0.004$ when comparing smoking between the no-exposure and high-exposure groups, $\mathrm{P}>0.05$ for all of the other comparisons, $\mathrm{BMI}=$ body mass index, NSAID = nonsteroidal anti-inflammatory drugs)

\begin{tabular}{|c|c|c|c|c|c|c|c|c|c|c|c|c|}
\hline \multirow[t]{3}{*}{ Characteristic } & \multicolumn{12}{|c|}{ Exposure } \\
\hline & \multicolumn{4}{|c|}{ Absent (128) } & \multicolumn{4}{|c|}{ Low (116) } & \multicolumn{4}{|c|}{ High (176) } \\
\hline & $\mathrm{N}$ & $\%$ & Mean & SD & $\mathrm{N}$ & $\%$ & Mean & SD & $\mathrm{N}$ & $\%$ & Mean & SD \\
\hline Age (years) & . & $\cdot$ & 42.03 & 4.7 & . & . & 42.62 & 3.8 & . & . & 42.20 & 3.6 \\
\hline \multicolumn{13}{|l|}{ Age classes } \\
\hline $\begin{array}{l}<35 \text { years } \\
35-55 \text { years } \\
>55 \text { years }\end{array}$ & $\begin{array}{l}36 \\
72 \\
20\end{array}$ & $\begin{array}{l}28.13 \\
56.25 \\
15.63\end{array}$ & i. & $\dot{.}$ & $\begin{array}{l}28 \\
64 \\
24\end{array}$ & $\begin{array}{l}24.14 \\
55.17 \\
20.69\end{array}$ & $\dot{.}$ & $\dot{.}$ & $\begin{array}{l}56 \\
80 \\
40\end{array}$ & $\begin{array}{l}31.82 \\
45.45 \\
22.73\end{array}$ & $\dot{.}$ & $\dot{.}$ \\
\hline Work seniority (years) & . & . & 14.96 & 1.9 & . & $\cdot$ & 13.86 & 2.1 & . & · & 12.52 & 4.1 \\
\hline $\mathrm{BMI}\left(\mathrm{kg} / \mathrm{m}^{2}\right)$ & 26.77 & . & $\cdot$ & $\cdot$ & 26.83 & . & $\cdot$ & $\cdot$ & 26.34 & . & $\cdot$ & $\cdot$ \\
\hline Shift workers & 52 & 40.62 & . & . & 52 & 44.83 & . & . & 80 & 45.45 & $\cdot$ & . \\
\hline Smokers & 68 & 53.13 & . & . & 52 & 44.83 & . & . & 64 & 36.36 & . & . \\
\hline Coffee drinkers ${ }^{a}$ & 32 & 25.00 & . & . & 32 & 27.59 & . & . & 32 & 18.18 & . & . \\
\hline Alcohol drinkers ${ }^{b}$ & 36 & 28.13 & . & . & 44 & 37.93 & . & . & 32 & 18.18 & $\cdot$ & $\cdot$ \\
\hline NSAID users & 4 & 3.13 & . & . & 4 & 3.45 & . & . & 8 & 4.55 & . & . \\
\hline
\end{tabular}

a More than three cups/day.

${ }^{b}$ More than $30 \mathrm{~g} /$ day.

Table 2. Prevalence of different types of dyspepsia among the exposed and unexposed workers. $(P=0.0002$ when comparing the prevalence of ulcer-like dyspepsia between the high-exposure and no-exposure groups, $\mathrm{P}=0.018$ when comparing the prevalence of ulcer-like dyspepsia between the high-exposure and low-exposure groups, $\mathrm{P}=0.001$ when comparing the prevalence of reflux-like dyspepsia between the high-exposure and no-exposure groups, $\mathrm{P}=0.006$ when comparing the prevalence of reflux-like dyspepsia between the low-exposure and no-exposure groups, $P<0.0001$ when comparing the cumulative prevalence of dyspepsia between the high-exposure and no-exposure groups, $P$ $=0.006$ when comparing the cumulative prevalence of dyspepsia between the low-exposure and no-exposure groups, $\mathrm{P}>0.05$ for all other comparisons)

\begin{tabular}{|c|c|c|c|c|c|c|}
\hline \multirow[t]{2}{*}{ Type of dyspepsia } & \multicolumn{2}{|c|}{$\begin{array}{l}\text { No exposure } \\
(\mathrm{N}=128)\end{array}$} & \multicolumn{2}{|c|}{$\begin{array}{l}\text { Low exposure } \\
\quad(\mathrm{N}=116)\end{array}$} & \multicolumn{2}{|c|}{$\begin{array}{l}\text { High exposure } \\
\quad(\mathrm{N}=176)\end{array}$} \\
\hline & N & $\%$ & N & $\%$ & N & $\%$ \\
\hline Ulcer-like & 15 & 11.71 & 20 & 17.24 & 52 & 29.54 \\
\hline Reflux-like & 15 & 11.71 & 28 & 24.14 & 44 & 25 \\
\hline Dismotility-like & 10 & 7.81 & 9 & 7.76 & 7 & 3.98 \\
\hline Nonspecific & 4 & 3.12 & 3 & 2.58 & 1 & 0.56 \\
\hline Total & 44 & 34.35 & 60 & 51.72 & 104 & 59.08 \\
\hline
\end{tabular}

The summary score, describing the severity of symptoms among the dyspeptic patients, was 36.81 (SD 29.64) for the high-exposure group, 27.18 (SD 34.44) for the lowexposure group, and 26.10 (SD 22.61) for the no-exposure group. The differences were not statistically significant.

Four variables associated with dyspepsia (ie, low exposure, high exposure, age $>55$ years, and alcohol consumption) were included in the final model of the stepwise regression analysis, as shown in table 5. The
Table 3. Prevalence of each dyspeptic symptom among the exposed and unexposed workers.

\begin{tabular}{|c|c|c|c|c|c|c|}
\hline \multirow[t]{2}{*}{ Symptom } & \multicolumn{2}{|c|}{$\begin{array}{c}\text { No exposure } \\
(\mathrm{N}=128)\end{array}$} & \multicolumn{2}{|c|}{$\begin{array}{l}\text { Low exposure } \\
\quad(\mathrm{N}=116)\end{array}$} & \multicolumn{2}{|c|}{$\begin{array}{l}\text { High exposure } \\
\quad(\mathrm{N}=176)\end{array}$} \\
\hline & N & $\%$ & N & $\%$ & N & $\%$ \\
\hline Nausea & 4 & 3.12 & 11 & 9.48 & 32 & 18.18 \\
\hline Heartburn & 28 & 21.87 & 30 & 25.86 & 44 & 25.00 \\
\hline Bloating & 1 & 0.78 & 15 & 12.93 & 36 & 20.45 \\
\hline Acid regurgitation & 23 & 17.96 & 22 & 18.96 & 44 & 25.00 \\
\hline Epigastric pain & 26 & 20.31 & 22 & 18.96 & 56 & 31.82 \\
\hline Epigastric discomfort & 13 & 10.15 & 18 & 15.51 & 32 & 18.18 \\
\hline Fullness & 4 & 3.12 & 8 & 6.89 & 16 & 9.09 \\
\hline Early satiety & 4 & 3.12 & 8 & 6.89 & 12 & 6.82 \\
\hline
\end{tabular}

Table 4. Likert scale regarding the frequency of symptoms among the dyspeptic patients, according to their degree of exposure to cement dust. ( $1=\leq 1$ time, $2=2-3$ times/week, $3=4-6$ times/week, $4=$ everyday)

\begin{tabular}{|c|c|c|c|c|c|c|}
\hline \multirow[t]{2}{*}{ Score } & \multicolumn{2}{|c|}{ No exposure ${ }^{a}$} & \multicolumn{2}{|c|}{ Low exposure b } & \multicolumn{2}{|c|}{ High exposure ${ }^{c}$} \\
\hline & N & $\%$ & N & $\%$ & $\mathrm{~N}$ & $\%$ \\
\hline 1 & 19 & 43 & 20 & 33 & 29 & 28 \\
\hline 2 & 14 & 32 & 18 & 30 & 28 & 27 \\
\hline 3 & 9 & 20 & 16 & 27 & 26 & 25 \\
\hline 4 & 2 & 5 & 6 & 10 & 21 & 20 \\
\hline
\end{tabular}

a $P$ for trend: no exposure 0.002 .

${ }^{b} \mathrm{P}$ for trend: low exposure 0.052 .

c $P$ for trend: high exposure 0.69 .

high-exposure variable showed the highest odds ratio (2.61), with the $95 \%$ confidence interval ranging from 1.62 to 4.20 . 
Table 5. Stepwise regression analysis with dyspepsia as a dependent variable and the unexposed workers as the reference group. ( $\mathrm{OR}=$ odds ratio, $95 \% \mathrm{Cl}=$ confidence interval)

\begin{tabular}{lcc}
\hline & OR & $95 \% \mathrm{Cl}$ \\
\cline { 2 - 3 } No exposure & 1.00 &.. \\
Age $>55$ years & 1.23 & $0.92-1.63$ \\
Alcohol consumption & 1.47 & $0.93-2.33$ \\
Low exposure & 1.94 & $1.15-3.27$ \\
High exposure & 2.61 & $1.62-4.20$ \\
\hline
\end{tabular}

\section{Discussion}

This study shows that dyspeptic symptoms are more frequent and more intense among cement workers exposed to dust when they are compared with unexposed workers. A peculiar pattern of dyspeptic symptoms (ulcer-like and reflux-like dyspepsia) was, in particular, associated with a substantial level of exposure to cement dust. The strength of the association, reported for the first time in our study, is supported by the following considerations: (i) the observation of a correlation with the degree of exposure and (ii) the reliability of the method of investigation for the assessment of dypepsia, which has been validated in many studies on this subject. Furthermore, it should be emphasized that our findings were obtained in a work environment characterized by a relatively low level of cement exposure (in no case was the limit of maximal allowed exposure exceeded, data not shown); the prevalence and degree of dyspepsia may be more marked in other contexts with higher exposure levels (20).

Interestingly, the prevalence of dyspepsia found for the reference group of unexposed workers was in the range of that reported in other studies of the general population $(21,22)$, a finding suggesting that the increased prevalence observed in the group of exposed workers can be considered correct.

The mechanism underlying the association between exposure to cement dust and dyspeptic symptoms remains speculative. We hypothesized that inhaled dust can be swallowed and thereby can act as an irritant of the mucosa of the upper-gastrointestinal tract. Indeed, it has been suggested that cement dust may have an abrasive effect on gastric mucosa (23), which may be at least in part due to the very high $\mathrm{pH}$ of the dust (24). This damaging action may lead to the development of dyspeptic symptoms in a substantial proportion of exposed persons, and, in a minority of persons with other predisposing conditions, to the development of gastric cancer in the long term.

A striking prevalence of ulcer-like dyspepsia, and, to a less degree, of reflux-like dyspepsia was observed among the workers exposed to cement dust when they were compared with the unexposed workers. In the gen- eral population of dyspeptic patients, the administration of proton pump inhibitors has been found to be effective in the management of patients with these kinds of dyspepsia, as convincingly shown by a recent meta-analysis on this subject (25), whereas these drugs are ineffective in cases of dismotility-like dyspepsia and unspecified dyspepsia (25). It would be interesting to know whether this treatment is effective even when chronic dust exposure represents the putative external factor involved in the development of ulcer-like or reflux-like dyspepsia. Alternative or concomitant measures could take the form of modifications of the work organization involving the temporary allocation of workers with severe dyspeptic symptoms exposed to high dust levels into areas of lower exposure.

The cut-off limit of $1 \mathrm{mg} / \mathrm{m}^{3}$ chosen for dust exposure in our present study was derived from recommendations concerning possible adverse effects on the respiratory system and may not be applicable to adverse effects on the gastrointestinal tract. Indeed, we found some increase in dyspeptic symptoms even among the workers exposed to levels below $1 \mathrm{mg} / \mathrm{m}^{3}$ (which is the "attention limit" for possible adverse effects on the respiratory system). This finding suggests that the gastrointestinal tract may be even more sensitive to cement dust exposure than the respiratory tract.

We focused on the possible confounding role of factors that may be associated with functional dyspepsia (ie, NSAID use, alcohol and coffee consumption, and smoking habits). We did not find any significant association between these factors and dyspepsia, but we did observe the lowest prevalence of smoking and alcohol consumption in the group with the highest prevalence of dyspepsia. Similar findings have been reported previously (26) and have been explained by the fact that the abstinence of putative offending agents is a common recommendation for dyspeptic patients in the early stages of the development of dyspepsia. The most likely explanation for our findings is therefore that lifestyle modifications introduced in the past in order to alleviate dyspeptic symptoms were the cause of our findings.

We did not perform a dietary evaluation in our population because the reliability of dietary questionnaires aiming at evaluating dietary habits over a period of several months is generally limited (27) and because the burden of evidence indicates that chronic dyspepsia is provoked by an abnormal response to food ingestion, and not by any peculiar diet (28). On the other hand, there are anedoctical reports that the ingestion of fatty meals may induce relapses in dyspeptic patients. We cannot therefore exclude the possibility that the increased frequency of symptoms among the dyspeptic patients in the high-exposure group was due to the lack of avoidance of fatty meals, although the mean BMI of this group, similar to that of the other two groups, 
does not support this hypothesis. In addition the low prevalence of alcohol consumption and smoking in this group suggests attention to the avoidance of possible triggering agents.

The main limitation of our study is represented by the lack of data on the $H$ pylori status of the examined workers. It should be noted, however, that all of the examined groups came from the same geographic area, had the same socioeconomic background, and were of the same gender (which are the main determinants for the prevalence of $H$ pylori infection in a given population) (29). Furthermore, the prevalence of dyspeptic patients whose symptoms are causally linked to the infection does not exceed 10\% (30-32). Thus an (improbable) imbalance in $H$ pylori infection between the three groups studied in our work would not explain the large differences in the prevalence of dyspepsia detected between the exposed and unexposed workers.

Another limitation of the study was that both the exposed and unexposed workers were men; therefore, the findings cannot be extrapolated to women. Although occupational exposure to cement dust should be infrequent among women (no eligible workers were female in our study), it is possible that dust exposure in other occupational and nonoccupational contexts may have different effects on dyspeptic symptoms among women.

It should be noted that work seniority was shorter for the high-exposure group than for the other two groups. This difference may reflect a certain selection effect, in which exposed workers seem to leave the workplace faster than unexposed workers. Should selection have occurred, the differences in the prevalence of dyspepsia between the exposed and unexposed workers may have been even larger than those reported by us. Another factor potentially affecting our findings may be the exclusion of patients with more severe forms of dyspepsia (those with organic disorders or with alarming symptoms). Once again, the inclusion of these patients would probably have reinforced our findings, given the detected association between cement-dust exposure and the severity of symptoms.

In conclusion, this study suggests that occupational exposure to cement dust is associated with dyspepsia in a dose-dependent manner and that the association is particularly strong for ulcer-like and reflux-like dyspepsia. Medical treatment or changes in work organization may alleviate the symptoms and reduce their potential impact on work performance.

\section{Acknowledgments}

The study was, in part, supported by a grant from the Tor Vergata University: fondi di ateneo 60\%/2006.

\section{References}

1. Wright WE, Bernstein L, Peters JM, Garabrant DH, Mack TM. Adenocarcinoma of the stomach and exposure to occupational dust. Am J Epidemiol. 1988;128:64-73.

2. Cocco P, Eard MH, Dosemeci M. Risk of stomach cancer associated with 12 workplace hazards: analysis of death certificates from 24 states of the United States with the aid of job exposure matrices. Occup Environ Med. 1999;56:781-7.

3. Smailyte G, Kurtinaitis J, Andersen A. Mortality and cancer incidence among Lithuanian cement workers. Occup Environ Med. 2004;61:529-34.

4. Ji J, Hemminky K. Socio-economic and occupational risk factors for gastric cancer: a cohort study in Sweden. Eur J Cancer Prev. 2006;15:391-7.

5. Kneller RW, Gao YT, McLaughlin JK, Gao RN, Blot WJ, Liu $\mathrm{MH}$, et al. Occupational risk factors for gastric cancer in Shangai, China. Am J Ind Med. 1990;18:69-78.

6. Jacobsson K, Attewell R, Hultgren B, Sjöland K. Gastrointestinal cancer among cement workers: a case-referent study. Int Arch Occup Eviron Health. 1990;62:337-340.

7. Amandus HE. Mortality from gastric cancer in United States cement plant and quarry workers, 1950-1980. Br J Ind Med. 1986;43:526-528.

8. Krstev S, Dosemeci M, Lissowska J, Chow W-H, Zatonsky W, Ward MH. Occupation and risk of stomach cancer in Poland. Occup Eviron Med. 2005;62:318-324.

9. Sjödal K, Jansson C, Bergdahl IA, Adami J, Boffetta P, Lagergren J. Airborne exposure and the risk of gastric cancer: a prospective cohort study. Int J Cancer. 2007;120:2013-18.

10. Severens JL, Laheij RJ, Jansen JB, Van der Lisdonk EH, Verbeek AL. Estimating the cost of lost productivity in dyspepsia. Aliment Pharmacol Ther. 1998;12:919-923.

11. Wahlqvist P, Carlsson J, Stålhammar N-O, Wiklund I. Validity of a work productivity and activity impairment questionnaire for patients with symptoms of gastro-esophageal reflux disease (WPAI-GERD) - results from a cross-sectional study. Value Health. 2002;5:106-113.

12. Haycox A, Einarson T, Eggleston A. The health economic impact of upper gastrointestinal symptoms in the general population: results from the domestic/international gastroenterology surveillance study (DIGEST). Scand J Gastroenterol. 1999;231:S38-S47.

13. Talley NU, Stanghellini V, Heading RC. Functional gastroduodenal disorders. Gut. 1999;45 suppl II:1137-42.

14. American Conference of Governmental Industrial Hygienists (ACGIH). Annual reports of the committees on threshold limit values \& biological exposure indices, year 2006. Cincinnati (OH): ACGIH; 2006. p 48.

15. European Committee for Standardization (CEN). Workplace atmosphere: size fraction definitions for measurements of airbone particles in the workplace. Brussels: CEN; 1993. CEN standard EN481.

16. Tuteja AK, Talley NJ, Gelmann SS, Adler SC, Thompson C, Tolman K, et al. Development of functional diarrhea, constipation, irritable bowel syndrome, and dyspepsia during and after traveling outside the USA. Dig Dis Sci. 2008;53(1):271-6.

17. Gargala G, Lecleire S, Francois A, Jacquot S, Dechelotte P, Ballet JJ, et al. Duodenal intraepithelial T lymphocytes in patients with functional dyspepsia. World J Gastroenterol. 2007;13:2333-8.

18. Minocha A, Wigington WG, Johnson WD. Detailed characterization of epidemiology of uninvestigated dyspepsia and its 
impact on quality of life among African Americans as compared to Caucasians. Am J Gastroenterol. 2006;101:336-342.

19. Treiber G, Schwabe M, Ammon S, Walker S, Klotz U, Malfertheiner P. Dyspeptic symptoms associated with Helicobacter pylori are influenced by strain and host specific factors. Aliment Pharmacol Ther. 2004;19:219-231.

20. Neghab M, Choobineh A. Work-related respiratory symptoms and ventilatory disorders among employees of a cement industry in Shiraz, Iran. J Occup Health. 2007;49:273-8.

21. Talley NU, Zinsmeister AR, Schleck CD, Melton RJ 3rd. Dyspepsia and dyspepsia subgroups: a population based study. Gastroenterology. 1992;102:1259-68.

22. Agreus L, Svardsudd K, Nyren O, Tibblin G. Irritable bowel syndrome and dyspepsia in the general population: overlap and lack of stability over time. Gastroenterology. 1995;109:671680.

23. Cocco P, Ward MH, Buiatti E. Occupational risk factors for gastric cancer: an overview. Epidemiol Rev. 1996;18:218234.

24. Calvert GM, Rice FL, Boiano JM, Sheehy JW, Sanderson WT. Occupational silica exposure and risk of various diseases: an analysis using death certificates from 27 states of the United States. Occup Environ Med. 2003;60:122-9.

25. Wang WH, Huang JQ, Zheng GF, Xia HH, Wong WM, Liu $\mathrm{XG}$, et al. Effects of proton pump inhibitors on functional dyspepsia: a meta-analysis of randomized placebo-controlled trails. Clin Gastroenterol Hepatol. 2007;5:178-85.

26. Moayyedi P, Forman D, Braunholtz D, Feltbower R, Crocombe W, Liptrott M, et al. The proportion of upper gastrointestinal symptoms in the community associated with Helicobacter pylori, lifestyle factors and nonsteroidal anti-inflammatory drugs. Am J Gastroenterol. 2000;95:1448-55.

27. Slimani R, Ferrari P, Ockè M, Welch A, Boeing H, Liere M, et al. Standardization of the 24-hour recall calibration method used in the European prospective investigation into cancer and nutrition (EPIC): general concepts and preliminary results. Eur J Clin Nutr. 2000;54:900-917.

28. Feinle-Bisset $\mathrm{C}$, Horowitz M. Review article: dietary factors in functional dyspepsia. Neurogastroenterol Mot. 2006;18:608 18.

29. Graham DY, Malaty HM, Evans DG, Evans DJ Jr, Klein PD, Adam E. Epidemiology of Helicobacter pylori in asymptomatic population in the United States: effects of age, race, and socioeconomic status. Gastroenterology. 1991;100:1495-501.

30. Matysiak-Budnik T, Laszewicz W, Lamarque D, Chaussade S. Helicobacter pylori and non malignant diseases. Helicobacter. 2006;11:suppl 1:27-31.

31. Hoffmann KM, Eherer AJ, Krejs GJ. Are dyspeptic symptoms linked to Helicobacter pylori?: a prospective cohort study among medical students. Wien Klin Wochenschr. 2003;115(56):175-8.

32. Quartero AO, Post MWM, Numans ME, de Melker RA, de Witt NJ. What makes the dyspeptic patient fell ill?: a cross-sectional survey of functional health status, Helicobacter pylori (H. pylori) infection, and psychological distress in dyspeptic patients in general practice. Gut. 1999;45:15-19.

Received for publication: 7 February 2008 